\title{
THE RELATION OF BLOOD PRESSURE TO WEIGHT, HEIGHT AND BODY SURFACE AREA IN SCHOOLBOYS AGED 11 TO 15 YEARS
}

\author{
BY \\ LEO HAHN \\ From the School Health Service, City of Leicester
}

(RECEIVED FOR PUBLICATION MAY 16, 1951)

In striking contrast to the abundant information we possess about the 'normal' blood pressure (B.P.) in adults our knowledge of what might be considered as the normal range of B.P. in school children is limited, and owing to the various methods used, of little avail for comparison. Blood pressure reading is not part of routine medical inspection, although it has been known for a long time that a normal person reaches his mature B.P. at about adolescence (Robinson and Brucer, 1939) and that the incidence of hypertension is as high at the age of 15 as it is at the age of $\mathbf{4 0}$ (Alvarez and Stanley, 1930). Hines (1937), using the 'cold-test', found $18^{\circ}$ o hypertension among schoolboys. The question of an early onset of essential hypertension is, therefore, a problem of preventive medicine. Yet, what is to be considered as the upper normal limit for the various years of age in this group? This problem is quite apart from the more important question of what is normal for the individual, which seems to receive confusingly discrepant answers. Robinson and Brucer (1939), in an investigation of 11,383 persons, described as the normal range for men and women of any age $90-120 \mathrm{~mm}$. systolic and $60-80 \mathrm{~mm}$. diastolic. Alvarez (1920) found an average of $126 \mathrm{~mm}$. in 16-year-old boys, and in 15,000 students $45^{\circ} \%$ with a systolic pressure over $130 \mathrm{~mm}$. and $22^{\circ}$ o over $140 \mathrm{~mm}$. Kylin (1937), in persons under 40 years, found a normal range of 90-130-140, and Hahn (1924) for the age group $10-40$ years a mean of $119 \cdot 2$ and a standard deviation of $15.9 \mathrm{~mm}$. Paterson and Moncrieff (1949) stated as the upper limit a systolic B.P. of $110 \mathrm{~mm}$. for 10-year-old and $120 \mathrm{~mm}$. for 14-year-old boys, regarding a B.P. as abnormal which is persistently $20 \mathrm{~mm}$. higher than the upper limit of the norm for the age. Taussig and Hecht (1938) reported as normal ranges for 10-year-old children 95-110 systolic, 60-70 diastolic: for 12-year-old children 102-115 systolic, 62-72 diastolic, and in 14-year-old children 104-124 systolic, 65-78 diastolic. Müller (1921), describing basal B.P. values for 11-14-year-old children, gave $80 \mathrm{~mm}$. systolic as night, and $100 \mathrm{~mm}$. as day, values for the systolic B.P.

In a preliminary report (Hahn, 1951) on the B.P. readings in 770 boys aged 11 to 15 years $I$ was able to demonstrate that if we regard $90-130 \mathrm{~mm}$. $\mathrm{Hg}$ as the normal range of systolic B.P. the percentage of hypertension is as high as $16 \cdot 2$ in the 14year-old and 26.6 in the 15-year-old boys. I was then faced with the problem whether, in view of the clinical and somatotypical aspect of the hypertensive group, the term 'hypertension' was really justified, or if in fact our notion about the normal range of B.P. in this age group should be revised. It soon became apparent that the boys with the best physique, mainly belonging to Kretschmer's athletic or pyknic type (as far as the latter type is recognizable at this age), fell into the 'hypertensive' group, and, notwithstanding the similarity of their somatotype to the physique usually present in the hypertensive adult, their B.P. appeared to be rather a functional correlative to the supernormal deviation of growth in general. The problem of normal and abnormal B.P. thus became a question of individual normality or abnormality and led to a statistical study of the relation between B.P. and anthropometric measurements in the age group under consideration.

In eight senior schools in the City of Leicester 1,417 boys were examined. All the measurements were carried out by one observer, myself. It is the purpose of this paper to establish standard figures based on the correlation of blood pressure, weight, 
height and body-surface area to determine whether in a given individual of this age group the B.P. is within normal limits.

\section{Material and Method}

Blood pressure readings were taken in the course of routine medical inspections, and all boys falling into the age group 11-15 years were examined. As the eight schools are scattered over the city, the sample includes boys coming from families of all social classes and can be considered a fair crosssection of an urban population. Excluded from the survey were cases with a history of renal disease, congenital and rheumatic heart disease, and hyperthyroidism. It is obvious that it was impossible to avoid the inclusion of pathological hypertensive cases due to such rarer causes as, for example, unilateral renal hypoplasia. Although basal B.P. measurements could not be achieved, care was taken that standard conditions were maintained. The reading was performed in the morning, always at the end of the routine examination, never after exercise, and in the sitting position. The sphygmomanometer used was Recklinghausen's tonometer gauged by a mercurial manometer. It must be stressed that, in contrast to similar investigations in adults, little apprehension was noted in the boys to whom the procedure was explained before the reading. The recommenda- tions given in the report of the Joint Committee of the Cardiac Societies of Great Britain and America (1939) were followed. Three successive readings were taken, and the lowest value of systolic and diastolic pressure used for statistical evaluation. Whenever the B.P. appeared to be high, the reading was repeated the next morning, in some cases a third time two days later.

\section{Results}

The age distribution of the 1,417 boys is set out in Table 1.

The distribution is uneven as mostly - leavers ' and new entrants were examined, and thus, if a greater sample of 12-, 13- and 15-year-olds was reviewed, slight correction of the data for these three ages might be expected.

Table 2 records the mean $\doteq$ standard error (S.E.), the standard deviation $(\sigma)$, the difference of the means, the coefficient of variation (C.V.) and the absolute range of systolic and diastolic B.P.

It can be seen from this table that, while in the 12-year-old boys the systolic mean is almost the same as in the 11-year-old boy, there is a rise in the mean systolic pressure from $13 \cdot 5$ years onwards, the age when puberty starts. The increase between $12 \cdot 5$ and $13 \cdot 5$ and between $13 \cdot 5$ and $14 \cdot 5$ exceeds by four times the standard error of the difference of the means.

TABLE 1

Age Distribution of Sample

\begin{tabular}{lllcccccc}
\hline Central age in years &. & $\ldots$ & $11 \cdot 5$ & $12 \cdot 5$ & $13 \cdot 5$ & $14 \cdot 5$ & $15 \cdot 5$ \\
Number of Boys &. & $\ldots$ & 211 & 126 & 118 & 880 & 82 & 1,417 \\
\hline
\end{tabular}

TABLE 2

Systolic and Diastolic Blood Pressure in 11 to 15-Year-old Boys

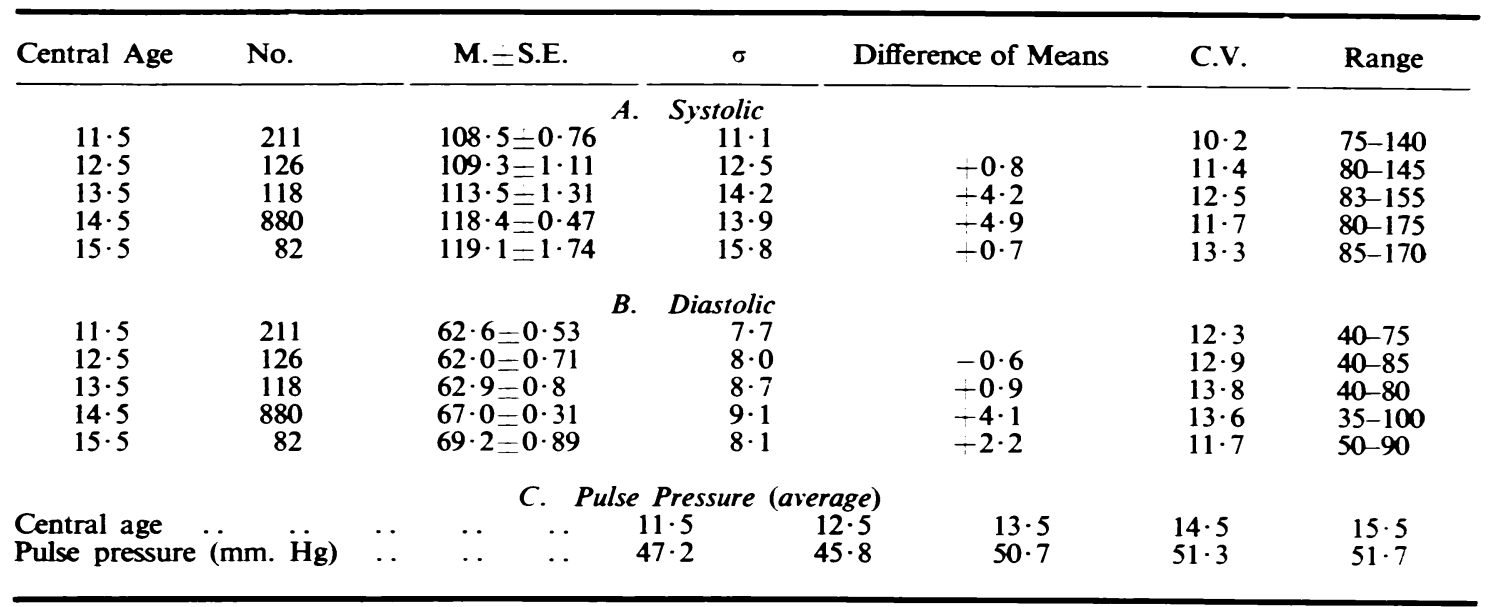


The changes of the diastolic blood pressure are much less conspicuous, showing a significant rise in the 14 and 15-year-old boys.

The pulse pressure is slightly higher in the 13 to 15-year-old boys, and the difference between this group and the prepubertal group is statistically significant.

Table 3 gives the percentage distribution of systolic and diastolic blood pressures for each year.

Fig. 1 illustrates that the peak of the frequency of the systolic blood pressure is shifted to the right in the 14and 15-year-old boys and that the distribution curve becomes flatter in the 15-yearold boys.

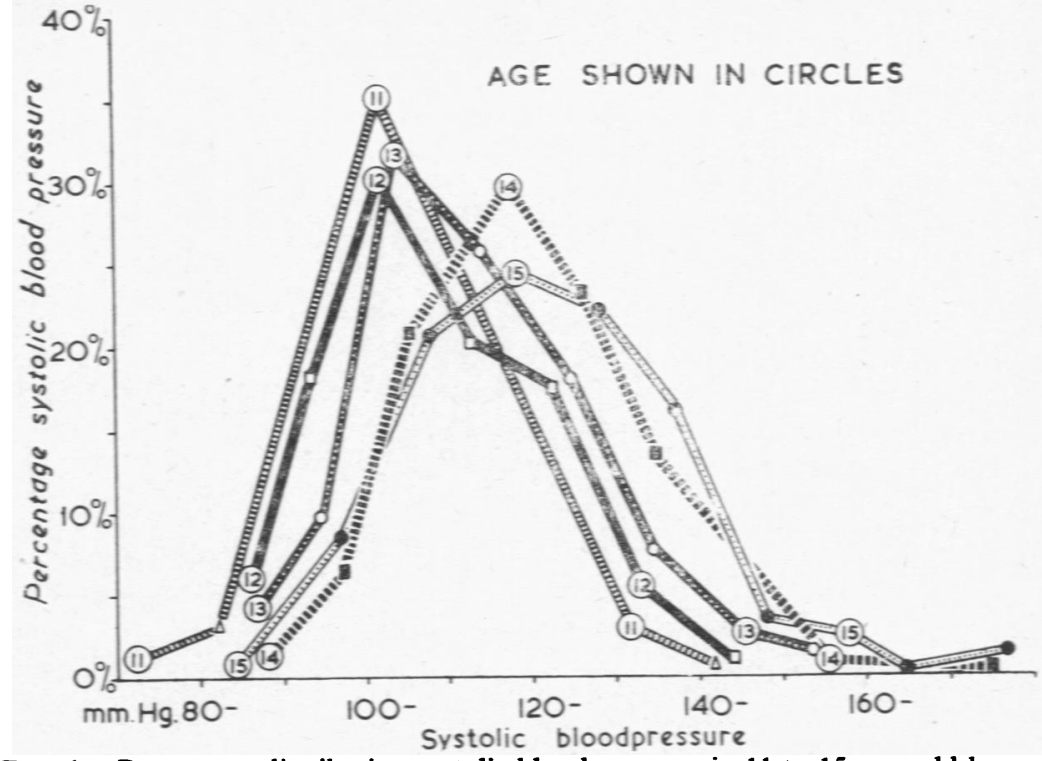

Fig. 1.-Percentage distribution systolic blood pressure in 11 to 15 -year-old boys.

TABLE 3

Percentage Distribution of Systolic and Diastolic Blood Pressure in 11 to 15-Year-old Boys

\begin{tabular}{|c|c|c|c|c|c|c|c|c|c|c|c|}
\hline \multirow{2}{*}{\multicolumn{2}{|c|}{$\frac{\text { Central Age }}{\text { (mm. Hg) }}$}} & \multicolumn{2}{|c|}{$11 \cdot 5$} & \multicolumn{2}{|c|}{$12 \cdot 5$} & \multicolumn{2}{|c|}{$13 \cdot 5$} & \multicolumn{2}{|c|}{$14 \cdot 5$} & \multicolumn{2}{|c|}{$15 \cdot 5$} \\
\hline & & No. & $\%$ & No. & $\%$ & No. & $\%$ & No. & $\%$ & No. & $\%$ \\
\hline $\begin{array}{c}70-79 \\
80-89 \\
90-99 \\
100-109 \\
110-119 \\
120-129 \\
130-139 \\
140-149 \\
150-159 \\
160-169 \\
170-179\end{array}$ & $\begin{array}{l}\ldots \\
\ldots \\
\ldots \\
\ldots \\
\ldots \\
\ldots \\
\ldots \\
\ldots\end{array}$ & $\begin{array}{r}2 \\
6 \\
40 \\
75 \\
50 \\
31 \\
6 \\
1 \\
0 \\
0 \\
0\end{array}$ & $\begin{array}{r}1 \cdot 0 \\
2 \cdot 9 \\
19 \cdot 0 \\
35 \cdot 4 \\
23 \cdot 7 \\
14 \cdot 6 \\
2 \cdot 9 \\
0 \cdot 5 \\
0 \cdot 0 \\
0 \cdot 0 \\
0 \cdot 0\end{array}$ & $\begin{array}{l}0 \\
7 \\
23 \\
38 \\
28 \\
22 \\
7 \\
1 \\
0 \\
0 \\
0\end{array}$ & $\begin{array}{c}\text { Systolic } \\
0 \cdot 0 \\
5 \cdot 6 \\
18 \cdot 2 \\
30 \cdot 1 \\
22 \cdot 2 \\
17 \cdot 5 \\
5 \cdot 6 \\
0.8 \\
0 \cdot 0 \\
0.0 \\
0.0\end{array}$ & $\begin{array}{r}0 \\
5 \\
11 \\
37 \\
30 \\
21 \\
9 \\
3 \\
2 \\
0 \\
0\end{array}$ & $\begin{array}{r}0 \cdot 0 \\
4 \cdot 3 \\
9 \cdot 3 \\
31 \cdot 3 \\
25 \cdot 4 \\
17 \cdot 9 \\
7 \cdot 6 \\
2 \cdot 5 \\
1 \cdot 7 \\
0 \cdot 0 \\
0 \cdot 0\end{array}$ & $\begin{array}{r}0 \\
10 \\
54 \\
182 \\
261 \\
202 \\
120 \\
37 \\
8 \\
5 \\
1\end{array}$ & $\begin{array}{r}0 \cdot 0 \\
1 \cdot 1 \\
6 \cdot 1 \\
20 \cdot 7 \\
29 \cdot 7 \\
23 \cdot 0 \\
13 \cdot 6 \\
4 \cdot 2 \\
0 \cdot 9 \\
0 \cdot 6 \\
0 \cdot 1\end{array}$ & $\begin{array}{r}0 \\
1 \\
7 \\
17 \\
20 \\
18 \\
13 \\
3 \\
2 \\
0 \\
1\end{array}$ & $\begin{array}{r}0 \cdot 0 \\
1 \cdot 2 \\
8 \cdot 5 \\
20 \cdot 7 \\
24 \cdot 4 \\
22 \cdot 0 \\
15 \cdot 9 \\
3 \cdot 7 \\
2 \cdot 4 \\
0 \cdot 0 \\
1 \cdot 2\end{array}$ \\
\hline Total & . & 211 & $100 \cdot 0$ & 126 & $100 \cdot 0$ & 118 & $100 \cdot 0$ & 880 & $100 \cdot 0$ & 82 & $100 \cdot 0$ \\
\hline $\begin{array}{l}90-129 \mathrm{~mm} . \\
130 \text { and abov } \\
140 \text { and abov }\end{array}$ & & & $\begin{array}{r}92 \cdot 7 \% \\
3 \cdot 4 \% \\
0 \cdot 5 \%\end{array}$ & & $\begin{array}{l}88 \% \\
6.4 \% \\
0.8 \%\end{array}$ & & $\begin{array}{r}83 \cdot 9 \% \\
11 \cdot 8 \% \\
4 \cdot 2 \%\end{array}$ & & $\begin{array}{l}79 \cdot 5 \% \\
19 \cdot 4 \% \\
5 \cdot 8 \%\end{array}$ & & $\begin{array}{r}75 \cdot 5^{\circ} \% \\
23 \cdot 3^{\circ} \% \\
7 \cdot 4^{\circ} \%\end{array}$ \\
\hline $\begin{array}{c}30-39 \\
40-49 \\
50-59 \\
60-69 \\
70-79 \\
80-89 \\
90-99 \\
100-109\end{array}$ & $\begin{array}{l}\ldots \\
\ldots \\
\ldots \\
\ldots \\
\ldots \\
\ldots\end{array}$ & $\begin{array}{r}0 \\
13 \\
56 \\
109 \\
33 \\
0 \\
0 \\
0\end{array}$ & $\begin{array}{r}0 \cdot 0 \\
6 \cdot 2 \\
26 \cdot 5 \\
51 \cdot 7 \\
15 \cdot 6 \\
0 \cdot 0 \\
0 \cdot 0 \\
0 \cdot 0\end{array}$ & $\begin{array}{r}0 \\
5 \\
42 \\
57 \\
19 \\
3 \\
0 \\
0\end{array}$ & $\begin{array}{c}\text { Diastolic } \\
0 \cdot 0 \\
4 \cdot 0 \\
33 \cdot 3 \\
45 \cdot 2 \\
15 \cdot 1 \\
2 \cdot 4 \\
0 \cdot 0 \\
0 \cdot 0\end{array}$ & $\begin{array}{r}0 \\
6 \\
38 \\
53 \\
17 \\
4 \\
0 \\
0\end{array}$ & $\begin{array}{r}0 \cdot 0 \\
5 \cdot 1 \\
32 \cdot 2 \\
44 \cdot 9 \\
14 \cdot 4 \\
3 \cdot 4 \\
0 \cdot 0 \\
0 \cdot 0\end{array}$ & $\begin{array}{r}1 \\
14 \\
169 \\
387 \\
249 \\
54 \\
5 \\
1\end{array}$ & $\begin{array}{r}0 \cdot 1 \\
1 \cdot 5 \\
19 \cdot 2 \\
44 \cdot 1 \\
28 \cdot 4 \\
6 \cdot 1 \\
0 \cdot 5 \\
0 \cdot 1\end{array}$ & $\begin{array}{r}0 \\
0 \\
10 \\
34 \\
33 \\
4 \\
1 \\
0\end{array}$ & $\begin{array}{r}0 \cdot 0 \\
0 \cdot 0 \\
12 \cdot 2 \\
41 \cdot 5 \\
40 \cdot 3 \\
4 \cdot 8 \\
1 \cdot 2 \\
0 \cdot 0\end{array}$ \\
\hline Total & . & 211 & $100 \cdot 0$ & 126 & $100 \cdot 0$ & 118 & $100 \cdot 0$ & 880 & $100 \cdot 0$ & 82 & $100 \cdot 0$ \\
\hline $\begin{array}{l}40-79 \\
80 \text { and above }\end{array}$ & $\cdots$ & & $\begin{array}{r}100 \cdot 0 \% \\
0.0 \%\end{array}$ & & $\begin{array}{r}97 \cdot 6 \% \\
2 \cdot 4 \%\end{array}$ & & $\begin{array}{r}96.6 \% \\
3.4 \%\end{array}$ & & $\begin{array}{r}93 \cdot 1 \% \\
6 \cdot 8 \%\end{array}$ & & $\begin{array}{r}94 \cdot 0 \% \\
6.0 \%\end{array}$ \\
\hline
\end{tabular}


From Table 3 it can be seen that whereas the percentage of systolic blood pressure for the range 90-129 is over $90 \%$ in the 11-year-old boys, this percentage decreases steadily to $88,83 \cdot 9,79 \cdot 5$ and 75.5 in the following years of age. If values over $130 \mathrm{~mm}$. were to be considered as hypertensive, the respective figures for the 13-, 14 and 15-year-old boys are climbing from 11.8 to 19.4 and $23.5 \%$; $78 \cdot 1^{\circ}$ o of the $11 \cdot 5$ and $70 \cdot 5^{\circ}$ of the $12 \cdot 5$-year-old boys have a systolic blood pressure between 90 and $119 \mathrm{~mm}$., while three-quarters of the $13 \cdot 5$ - and 14.5-year-old-boys show a systolic blood pressure between 100 and $129 \mathrm{~mm}$. Of the $15 \cdot 5$-year-old boys, $62 \cdot 3 \%$ have a systolic blood pressure between 110 and $139 \mathrm{~mm}$.

For the diastolic blood pressure the range of highest frequency is much more limited. For all the ages concerned, the percentage covering the range $40-79$ is over $90^{\circ}$. and values above $80 \mathrm{~mm}$., which could be considered as diastolic hypertension, reach $6 \cdot 8$ and $6.0^{\circ} \%$ in the $14 \cdot 5$ - and $15 \cdot 5$-year-old boys only.

Of the 11.5-, 12.5- and 13.5-year-old boys $78 \cdot 2,78 \cdot 5$ and $77 \cdot 1^{\circ}$ o have a diastolic blood pressure between 50 and $69 \mathrm{~mm}$., while 72.5 and $81 \cdot 8^{\circ}$; of the $14 \cdot 5$ - and $15 \cdot 5$-year-old boys fall within the range of 60 to $79 \mathrm{~mm}$. diastolic blood pressure.

\section{Correbation between Systolic and Diastolic Blood Pressure}

The diastolic blood pressure, as can be observed from the values of the pulse pressure given in Table 2, follows the pattern of the systolic blood pressure, i.e. rises with it. The correlation coefficient and the regression equation was determined for each age group and the results are given in Table 4 .

in one characteristic for a unit change in the other. Thus, the diastolic blood pressure rises if the systolic pressure increases by $10 \mathrm{~mm}$. $\mathrm{Hg}$ for the following ages :-

11-year-old by $3.3 \mathrm{~mm}$. Hg
12-year-old by $4.1 \mathrm{~mm}$. Hg
13-year-old by $4.0 \mathrm{~mm}$. Hg
14-year-old by $2.9 \mathrm{~mm}$. Hg
15-year-old by $2.1 \mathrm{~mm}$. Hg

From the equation given in the last column of Table 4 the diastolic blood pressure corresponding to a given systolic value can easily be predicted.

\section{Blood Pressure and Growth}

The survey so far has shown that in the average boy B.P. 'spurts' at about $13 \cdot 5$ years of age, that is when puberty has set in, with its dramatic bodily changes characterizing the third period of acceleration of growth. But variation is more than ever at work and no rigid pattern can be observed. Genetically determined it is the constellation of the whole ensemble of the ductless glands which, under the direction of the anterior lobe of the pituitary, will decide for the individual boy not only the onset but also the extent of the phenomena that are produced by the impact of the hormones released by the pituitary gland. Environmental influences, too, will interfere in a positive or negative direction and thus height and weight as well as functional features vary from boy to boy during this revolutionary period of life. The blood pressure follows the pattern of growth and its rate of increase is governed by the laws of the boys' constitution. The physiological, not the chronological, age is decisive for the place he is to achieve with regard to his physique and his blood pressure.

Blood Pressure and General Condition. It has been mentioned before that if in a rough and ready

TABLE 4

Correlation Between Systolic and Diastolic Blood Pressure in 11 to 15-Year-old Boys

\begin{tabular}{|c|c|c|c|c|c|}
\hline Central Age & No. & Corr. Coeff. & S.E. & $\begin{array}{l}\text { Regression } \\
\text { Coeff. }\end{array}$ & Diastolic B.P.* \\
\hline $\begin{array}{l}11 \cdot 5 \\
12 \cdot 5 \\
13 \cdot 5 \\
14 \cdot 5 \\
15 \cdot 5\end{array}$ & $\begin{array}{r}211 \\
126 \\
118 \\
880 \\
82\end{array}$ & $\begin{array}{l}+0.499 \\
+0.658 \\
+0.646 \\
+0.44 \\
+0.412\end{array}$ & $\begin{array}{l}=0.068 \\
=0.083 \\
=0.092 \\
=0.033 \\
=0.11\end{array}$ & $\begin{array}{l}0 \cdot 332 \\
0 \cdot 405 \\
0 \cdot 396 \\
0 \cdot 288 \\
0 \cdot 211\end{array}$ & $\begin{array}{l}=0.33 \times \text { syst. }+25.7 \\
=0.41 \times \text { syst. }+17.2 \\
=0.40 \times \text { syst. }-17.5 \\
=0.29 \times \text { syst. }-32.8 \\
=0.21 \times \text { syst. }+44.2\end{array}$ \\
\hline
\end{tabular}

- Calculated from regression equation.

As can be seen from Table 4 the correlation between systolic and diastolic blood pressure is positive for all ages and significant as shown by the standard error. The regression coefficient demonstrates the change which, according to the line representing the regression equation, takes place way a B.P. of $129 / 79$ is regarded as the upper limit of normal for the age-group under consideration, the boys belonging to the 'hypertensive' group were in the majority conspicuous for their good, very often excellent physique. Furthermore, and here nutrition may be the decisive factor, it could be 
noticed that the average systolic B.P. of boys in schools serving districts of lower income groups was distinctly lower than the respective values for boys coming from higher income groups.

As a practical preliminary step it seemed profitable to assess the relation of B.P. to physique by comparing the general condition in hypertensive and non-hypertensive boys using the customary grading in the medical inspection schedules. 'A', ' $B$ ' and ' $C$ ' thereby denote ' good ', ' fair ' and 'poor' according to the impression the observer obtains from nutrition, muscle tone, turgor and vascularization of the skin, posture, facial expression and mental alertness of the examinee. This evaluation, though necessarily subjective in its nature, should be admissible if employed by one observer only, as was the case in the sample under consideration.

In Table 5, 880 boys, of 14 years of age, hypertensive and non-hypertensive, are tabulated according to their systolic B.P. and general condition.
The difference between the proportions of $A$ in hypertensives and non-hypertensives is $19.1 \%$; as the standard error of the difference between these two proportions is $3.6 \%$, the difference can be considered as highly significant. The mean of the systolic blood pressure is significantly higher in the A group than in the B group, whilst the diastolic B.P., being 72,72 and $71 \mathrm{~mm}$. respectively, is practically the same in all groups.

\section{Blood Pressure, Weight and Height in 11 to 15-Year-old Boys}

The features of growth before and in puberty are well known and it is not proposed to discuss them here in detail. Table 6, which gives the statistical data, demonstrates the spurt in weight and height starting at about 13.5 years of age. Considering the relatively small volume of the sample, the values obtained are well in conformity with the standard

TABLE 5

General Condinon in 880 Boys

\begin{tabular}{lcccc}
\hline & A (Good) & B (Fair) & C (Poor) \\
\cline { 2 - 4 } Total & 880 & $11 \cdot 9 \%$ & $67 \cdot 1 \%$ & $21 \cdot 0 \%$ \\
Hypertensives & 172 & $27 \cdot 3 \% \pm 3 \cdot 39 \%$ & $64 \cdot 5 \%$ & $8 \cdot 2 \%$ \\
Non-hypertensive & 708 & $8 \cdot 2 \% \pm 1 \cdot 03 \%$ & $67 \cdot 8 \%$ & $24 \cdot 0 \%$ \\
\hline Mean systolic B.P. in & $127 \cdot 5$ & $119 \cdot 0$ & $110 \cdot 8$ \\
& $\pm 1 \cdot 15$ & \pm 0.52 & \pm 0.95
\end{tabular}

TABLE 6

Weight and Height in 11 to 15-Year-old Boys

\begin{tabular}{|c|c|c|c|c|c|c|}
\hline Central Age & No. & M. & S.E. & $\sigma$ & C.v. & Range \\
\hline $11 \cdot 5$ & 211 & \multirow{5}{*}{$\begin{array}{l}35 \cdot 03 \\
77 \cdot 1 \mathrm{lb} . \\
36 \cdot 4 \\
80 \mathrm{lb} . \\
41 \cdot 5 \\
91 \cdot 3 \mathrm{lb} . \\
46 \cdot 65 \\
102 \cdot 5 \mathrm{lb} . \\
52 \cdot 8 \\
116 \cdot 2 \mathrm{lb} .\end{array}$} & $\begin{aligned} & \text { Weight } \\
= & 0 \cdot 35 \mathrm{~kg} .\end{aligned}$ & \multirow{5}{*}{$\begin{array}{c}5 \cdot 12 \mathrm{~kg} . \\
11 \cdot 3 \mathrm{lb} . \\
6.9 \mathrm{~kg} . \\
15 \cdot 2 \mathrm{lb} . \\
8 \cdot 2 \mathrm{~kg} . \\
18 \cdot 04 \mathrm{lb} . \\
8 \cdot 96 \mathrm{~kg} . \\
19 \cdot 7 \mathrm{lb} . \\
9 \cdot 6 \mathrm{~kg} . \\
21 \cdot 1 \mathrm{lb} .\end{array}$} & $14 \cdot 6$ & \multirow{5}{*}{$\begin{array}{l}25 \cdot 5-53 \cdot 6 \mathrm{~kg} . \\
56-118 \mathrm{lb} . \\
22 \cdot 3-72 \cdot 2 \mathrm{~kg} . \\
47-158 \mathrm{lb} . \\
27 \cdot 7-63 \cdot 6 \mathrm{~kg} . \\
61-140 \mathrm{lb} . \\
29 \cdot 5-81 \cdot 8 \mathrm{~kg} . \\
64 \cdot 9-178 \mathrm{lb} . \\
31 \cdot 8-75 \cdot 9 \mathrm{~kg} . \\
70-177 \mathrm{lb} .\end{array}$} \\
\hline $12 \cdot 5$ & 126 & & & & $18 \cdot 9$ & \\
\hline $13 \cdot 5$ & 118 & & $=0.76 \mathrm{~kg}$ & & $19 \cdot 7$ & \\
\hline $14 \cdot 5$ & 880 & & $=0.30 \mathrm{~kg}$. & & $19 \cdot 2$ & \\
\hline $15 \cdot 5$ & 82 & & $=1.06 \mathrm{~kg}$. & & $18 \cdot 1$ & \\
\hline $11 \cdot 5$ & 211 & \multirow{5}{*}{$\begin{array}{c}140 \cdot 2 \\
56 \cdot 1 \text { in. } \\
143.8 \\
57.6 \text { in. } \\
150.5 \text { in. } \\
60.2 \text { in. } \\
156.5 \\
62.6 \text { in. } \\
162.8 \\
65.1 \text { in. }\end{array}$} & $\begin{array}{c}\text { Height } \\
=0.44 \mathrm{~cm} .\end{array}$ & \multirow{5}{*}{$\begin{array}{l}6.35 \mathrm{~cm} . \\
2.5 \mathrm{in} . \\
7.95 \mathrm{~cm} . \\
3.2 \mathrm{in} . \\
8.1 \mathrm{~cm} . \\
3.24 \mathrm{in} . \\
9.0 \mathrm{~cm} . \\
3.6 \mathrm{in} . \\
9.8 \mathrm{~cm} . \\
3.9 \mathrm{in} .\end{array}$} & $4 \cdot 4$ & \multirow{5}{*}{$\begin{array}{l}127-156 \mathrm{~cm} . \\
50 \cdot 8-62 \cdot 4 \mathrm{in} . \\
125-175 \mathrm{~cm} . \\
50-70 \mathrm{in} . \\
127-170 \mathrm{~cm} . \\
50 \cdot 8-68 \mathrm{in} . \\
122 \cdot 5-182 \cdot 5 \mathrm{~cm} \\
49-73 \mathrm{in} . \\
137 \cdot 5-185 \mathrm{~cm} . \\
55-74 \mathrm{in} .\end{array}$} \\
\hline $12 \cdot 5$ & 126 & & & & $5 \cdot 5$ & \\
\hline $13 \cdot 5$ & 118 & & $=0.75 \mathrm{~cm}$. & & $5 \cdot 4$ & \\
\hline $14 \cdot 5$ & 880 & & $=0.30 \mathrm{~cm}$. & & $5 \cdot 7$ & \\
\hline $15 \cdot 5$ & 82 & & $\doteq 1.09 \mathrm{~cm}$. & & $6 \cdot 0$ & \\
\hline
\end{tabular}


figures presented in larger statistics, as for instance in the recently published work of Sutcliffe and Canham (1950).

As shown in Table 6 the average increase in weight is $1.4 \mathrm{~kg}$. and in height $3.6 \mathrm{~cm}$. between $11 \cdot 5$ and $12 \cdot 5$ years and rises to $5 \cdot 1,5 \cdot 2$ and $6 \cdot 1 \mathrm{~kg}$; $6 \cdot 7,6 \cdot 0$ and $6 \cdot 3 \mathrm{~cm}$. for the ages $12 \cdot 5-13 \cdot 5$, $13 \cdot 5-14 \cdot 5$ and $14 \cdot 5-15 \cdot 5$. Yet the steady rise of the standard deviation after the beginning of puberty illustrates the well established fact that, during this critical period, boys of the same age differ considerably in their growth; some reach puberty before 13.5 years and many lag behind and have not attained puberty at the age of 15 years, which, for British boys is the median age at which adolescence is attained (Ellis, 1950). In weight and height these latter boys often represent the average values of a 12- or 13-year-old boy; in other words, their physiological age or their weight- or height-age is that of a.boy of 12 or 13 years.

Blood pressure in this age group follows the same pattern as can be seen in Fig. 2 giving the average values of weight, height and B.P. for the years $11 \cdot 5$ to $15 \cdot 5$.

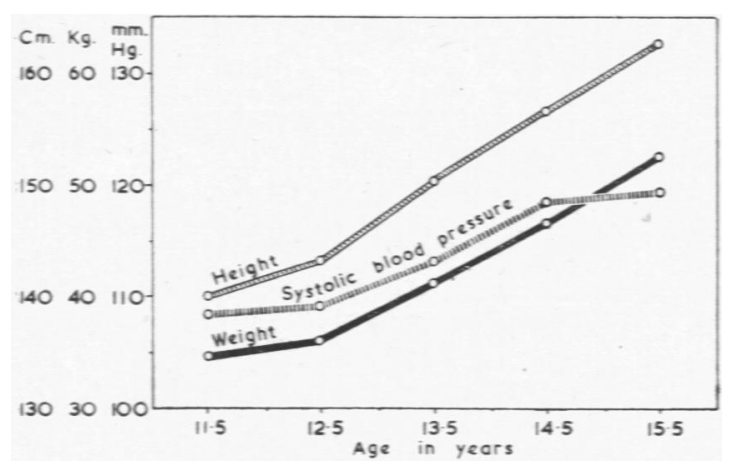

FIG. 2.-Mean systolic blood pressure, weight and height in 11 to 15-year-old boys.

In adults there is a correlation between hypertension and overweight (Koller, 1936). Robinson and Brucer (1940), in a study of B.P. and body build based on the findings in 3,658 persons, found a positive correlation between body build and B.P., men and women of 'lateral or broad build' sthenic type representing systolic hypertension four times as frequently as the asthenic, linear type, and dias 'olic hypertension seven times more frequently.

In order to ascertain whether there is any correlation between weight, height and B.P. within their respective natural variations, the correlation coefficients ( $r$ ) were calculated. The results for each age group are given in Table 7.
In all five ages the correlation coefficient is positive both for B.P. and weight and B.P. and height and exceeds twice the standard error of the correlation coefficient. The association is closest for B.P. and weight and B.P. and height in the 13.5-year-old boys. From the regression equation as given in Table 7 it is possible to predict the systolic blood pressure which to a certain degree appears to be normal for a given weight or height. As an example values for the systolic blood pressure for each year of age obtained in such a way are computed in Table 8.

It can be observed that in the central part of Table 8 , within an area covering roughly the range between $M-1 S . D$. and $M-1 S . D$. of the weight representing the respective year, the expected values of systolic blood pressure differ only slightly for the same weights irrespective of age. Thus a boy appears to have the blood pressure of his physiological age as it is manifested in his weight. Take, for example, a boy whose age is $\mathbf{1 4 . 5}$ and whose weight is $35 \mathrm{~kg}$. (5 st. $7 \mathrm{lb}$.), his physiological age is then (Table 6), according to his weight, about that of the average $11 \cdot 5$-year-old boy and his systolic B.P. that of the average $11 \cdot 5$-year-old, i.e. $108 \cdot 5 \mathrm{~mm}$. As his weight deviates from the mean of his age by $-11.6 \mathrm{~kg}$., his blood pressure should deviate from the mean of his age (Table 2) by $-11.6 \times 0.6$, i.e. $-7 \mathrm{~mm}$., which means $111.4 \mathrm{~mm}$. expected B.P. (Table 8 gives the value $111.4 \mathrm{~mm}$. $\mathrm{Hg}$ ). Suppose that the weight of a $14 \cdot 5$-year-old boy is $53 \mathrm{~kg}$., i.e. the mean weight of $15 \cdot 5$-year-old boys whose mean systolic B.P. is $119 \cdot 1$, his expected B.P. therefore, according to the regression equation for his age, is $122 \cdot 2$, and according to the equation for the $15 \cdot 5$-year-old boys, $119 \cdot 2 \mathrm{~mm}$. $\mathrm{Hg}$, which shows that the formula corresponding to his weight-age should be applied.

Comparison of the expected systolic B.P. $=5 \mathrm{~mm}$. $\mathrm{Hg}$ with the actual systolic B.P. readings suggests that the normal B.P. for boys with proportionate weight and height measurements can be predicted by using the regression equations. In boys, however, with either excessive weight, as in cases of pituitary obesity, or excessive height, as in hypogonadism. the formulae are not always applicable as in both conditions there is a tendency to arterial hypotension. The fact that boys belonging to those groups are included in the statistical evaluation of this survey makes it probable that by using a much greater volume as basis for the calculations corrections will occur.

Blood Pressure and Body Surface Area

Considering the association which exists between systolic B.P. and weight and height, the use of one 
TABIE 7

Data Relating Blood Pressure, Weght and Hegght

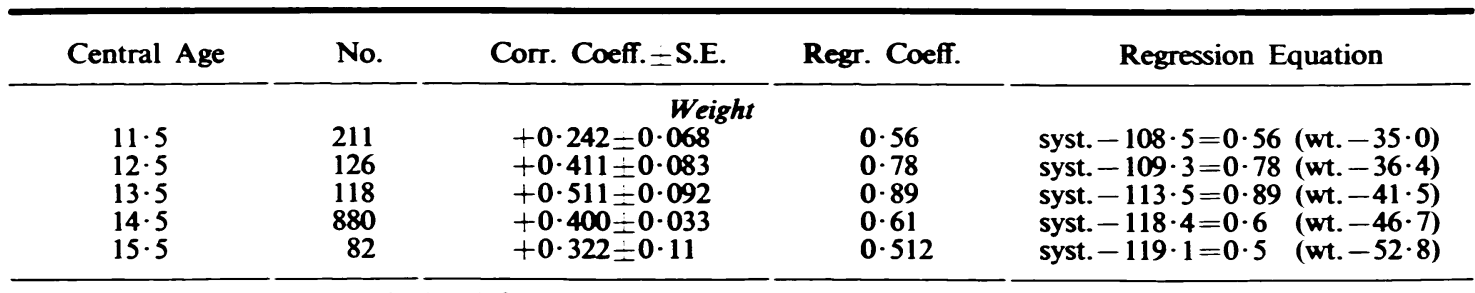

Systolic blood pressure as calculated from the regression equation

Central age $11.5 \quad 12 \cdot 5 \quad 13 \cdot 5$

Systolic B.P. : $=0.56 \times w t .+88.9 ; 0.78 \times w t .+80.9 ; 0.89 \times w t .+76.3 ; 0.6 \times w t .+90.4 ; 0.5 \times w t .+92.7$

With each kg. rise

in weight B.P. rises by $\ldots 0.56 \mathrm{~mm}$.

$0.78 \mathrm{~mm}$.

$0.89 \mathrm{~mm}$.

$0.6 \mathrm{~mm}$.

$0.5 \mathrm{~mm}$.

\begin{tabular}{|c|c|c|c|c|}
\hline $\begin{array}{l}11 \cdot 5 \\
12 \cdot 5 \\
13 \cdot 5 \\
14 \cdot 5 \\
15 \cdot 5\end{array}$ & $\begin{array}{r}211 \\
126 \\
118 \\
880 \\
82\end{array}$ & $\begin{array}{ll} & \text { Height } \\
+0.229 & 0.068 \\
+0.299 & =0.083 \\
+0.483 & 0.092 \\
+0.309 & 0.033 \\
+0.444 & =0.11\end{array}$ & $\begin{array}{l}0 \cdot 429 \\
0.492 \\
0 \cdot 852 \\
0 \cdot 469 \\
0 \cdot 715\end{array}$ & $\begin{array}{l}\text { syst. }-108 \cdot 5=0 \cdot 43 \text { (ht. }-140 \cdot 2) \\
\text { syst. }-109 \cdot 3=0 \cdot 49 \text { (ht. }-143 \cdot 8) \\
\text { syst. }-113 \cdot 5=0 \cdot 85 \text { (ht. }-150 \cdot 5) \\
\text { syst. }-118 \cdot 4=0 \cdot 47 \text { (ht. }-156 \cdot 5) \\
\text { syst. }-119 \cdot 1=0 \cdot 71 \text { (ht. }-162 \cdot 8)\end{array}$ \\
\hline
\end{tabular}

Systolic blood pressure as calculated from regression equation

Central Age 11.5 12.5 13.5

$14 \cdot 5 \quad 15 \cdot 5$

Systolic B.P. : $-0.43 \times$ ht. $+48 \cdot 2 ； 0.49 \times$ ht. $+38 \cdot 7 ； 0.85 \times$ ht. $-14 \cdot 5 ; 0.47 \times$ ht. $+44 \cdot 8 ; 0.71 \times$ ht. $+3 \cdot 5$

With each cm. rise in

height systolic B.P. rises by $0.43 \mathrm{~mm}$. $\quad 0.49 \mathrm{~mm}$. $\quad 0.85 \mathrm{~mm}$. $\quad 0.47 \mathrm{~mm}$. $\quad 0.71 \mathrm{~mm}$.

TABLE 8

Expected Systouc blood Pressure Calculated from the Regression Equation blood Pressure and WEGHT

\begin{tabular}{|c|c|c|c|c|c|c|c|c|c|c|}
\hline \multirow[b]{2}{*}{ Age } & \multicolumn{10}{|c|}{ Weight (kg.) } \\
\hline & 25 & 30 & 35 & 40 & 45 & 50 & 55 & 60 & 65 & 70 \\
\hline $11 \cdot 5$ & $102 \cdot 9$ & $105 \cdot 7$ & $108 \cdot 5$ & $111 \cdot 3$ & $114 \cdot 1$ & $116 \cdot 9$ & $119 \cdot 7$ & & & \\
\hline $12 \cdot 5$ & $100 \cdot 4$ & $104 \cdot 3$ & $108 \cdot 2$ & $112 \cdot 1$ & $116 \cdot 0$ & $119 \cdot 9$ & $123 \cdot 8$ & & & \\
\hline $13 \cdot 5$ & $98 \cdot 6$ & $103 \cdot 0$ & $107 \cdot 5$ & $111 \cdot 9$ & $116 \cdot 4$ & $120 \cdot 8$ & $125 \cdot 3$ & $129 \cdot 7$ & $134 \cdot 2$ & \\
\hline $14 \cdot 5$ & & $108 \cdot 4$ & $111 \cdot 4$ & $114 \cdot 4$ & $117 \cdot 4$ & $120 \cdot 4$ & $123 \cdot 4$ & $126 \cdot 4$ & $129 \cdot 4$ & $135 \cdot 4$ \\
\hline $15 \cdot 5$ & & $107 \cdot 7$ & $110 \cdot 2$ & $112 \cdot 7$ & $115 \cdot 2$ & $117 \cdot 7$ & $120 \cdot 2$ & $122 \cdot 7$ & $125 \cdot 2$ & $127 \cdot 7$ \\
\hline
\end{tabular}

of the indices of physique combining both measurements recommends itself. Of the many formulae available the body surface area (B.S.A.) was chosen, not only because of its well known connexion with the basal metabolic rate but mainly for the reason that the size of heart, the stroke volume, as well as the area of the total vascular bed and with it the peripheral resistance, all decisive factors of the arterial B.P., are proportionate to the B.S.A. The body surface area was calculated from DuBois's formula, i.e. B.S.A. weight $\mathrm{t}^{0.425} \times$ height $\mathrm{t}^{0.725} \times 71 \cdot 84$ and a chart of the corresponding values is given as Appendix 1.

Table 9 summarizes the correlation between systolic B.P. and B.S.A. The correlation is positive throughout, being highest in the $12 \cdot 5$ - and 13-5-year-old boys. The correlation coefficient exceeds in all the examined groups three times its standard error and is therefore significant. The regression coefficient, or in other words, the slope 
TABLE 9

Correlation of Systolic B.P. and Body Surface Area

\begin{tabular}{|c|c|c|c|c|c|c|c|}
\hline Age & $\begin{array}{c}\text { No. of } \\
\text { Boys }\end{array}$ & $\begin{array}{c}\text { Mean } \\
\text { Systolic B.P. }\end{array}$ & $\begin{array}{l}\text { S.D. Systolic } \\
\text { B.P. }\end{array}$ & $\begin{array}{l}\text { Mean } \\
\text { B.S.A. }\end{array}$ & S.D. B.S.A. & $\begin{array}{l}\text { Correlation } \\
\text { and S.E. of } r\end{array}$ & $\begin{array}{l}\text { Regression } \\
\text { Coeff. }\end{array}$ \\
\hline $\begin{array}{l}11 \cdot 5 \\
12 \cdot 5 \\
13 \cdot 5 \\
14 \cdot 5 \\
15 \cdot 5\end{array}$ & $\begin{array}{l}202^{*} \\
117^{*} \\
109^{*} \\
873^{*} \\
82\end{array}$ & $\begin{array}{l}108 \cdot 1 \\
109 \cdot 5 \\
113 \cdot 8 \\
118 \cdot 0 \\
119 \cdot 1\end{array}$ & $\begin{array}{l}11 \cdot 9 \\
13 \cdot 3 \\
13 \cdot 2 \\
13 \cdot 4 \\
15 \cdot 8\end{array}$ & $\begin{array}{l}1 \cdot 17 \\
1 \cdot 19 \\
1 \cdot 32 \\
1 \cdot 43 \\
1 \cdot 55\end{array}$ & $\begin{array}{l}0 \cdot 09 \\
0 \cdot 12 \\
0 \cdot 13 \\
0 \cdot 17 \\
0 \cdot 18\end{array}$ & $\begin{array}{l}0 \cdot 311=0.07 \\
0 \cdot 419=0.092 \\
0 \cdot 431=0.096 \\
0 \cdot 401=0.034 \\
0 \cdot 409=0.11\end{array}$ & $\begin{array}{l}41 \cdot 1 \\
46 \cdot 43 \\
45 \cdot 51 \\
32 \cdot 56 \\
35 \cdot 73\end{array}$ \\
\hline
\end{tabular}

Regression Equation and Systolic B.P. Calculated from Regression Equation

\begin{tabular}{|c|c|c|}
\hline Age & Regression Equation & Systolic B.P. \\
\hline $\begin{array}{l}11 \cdot 5 \\
12 \cdot 5 \\
13 \cdot 5 \\
14 \cdot 5 \\
15 \cdot 5\end{array}$ & $\begin{array}{l}\text { systol. B.P. }-108 \cdot 1=41 \cdot 1 \text { (B.S.A. }-1 \cdot 17) \\
\text { syst. B.P. } 109 \cdot 5=46 \cdot 4(\text { B.S.A. }-1 \cdot 19) \\
\text { syst. B.P. }-113 \cdot 8=45 \cdot 51 \text { (B.S.A. }-1 \cdot 32) \\
\text { syst. B.P. } 118 \cdot 0=32 \cdot 56 \text { (B.S.A. }-1 \cdot 43) \\
\text { syst. B.P. }-119 \cdot 1=35 \cdot 7 \text { (B.S.A. }-1 \cdot 55)\end{array}$ & $\begin{array}{l}\text { syst. }=41 \quad * \text { B.S.A. }+60 \cdot 1 \\
\text { syst. }=46 \quad * \text { B.S.A. }+54 \cdot 3 \\
\text { syst. }=45 \cdot 5 \text { B.S.A. }+53 \cdot 7 \\
\text { syst. }=32 \cdot 6 \quad \text { B.S.A. }+71 \cdot 4 \\
\text { syst. }=35 \cdot 7 \text { B.S.A. }+63 \cdot 7\end{array}$ \\
\hline
\end{tabular}

- Cases of pituitary obesity were excluded as the B.S.A. formula is not applicable in this condition. Therefore means and S.D. differ slightly from the previously given values.

of the line representing the equation, varies but little (Fig. 3) for the various ages. Thus, the association between B.S.A. and B.P. seems to be closer than that of blood pressure and age in the age groups under consideration. This is demonstrated in Table 10 which gives the values of systolic blood pressure as calculated from the regression equation for each year. It will be noted that there is, with the exception of the 15-5-year-group, but little difference in the calculated values of the systolic B.P. for the same B.S.A. in all ages.
For each $0 \cdot 1$ square metre of increase of B.S.A. the systolic blood pressure rises in the following age groups :-

11-year-old by $4.1 \mathrm{~mm}$. $\mathrm{Hg}$

12-year-old by $4.6 \mathrm{~mm}$. Hg

13-year-old by $4.6 \mathrm{~mm}$. $\mathrm{Hg}$

14-year-old by $3.3 \mathrm{~mm}$. $\mathrm{Hg}$

15 -year-old by $3.6 \mathrm{~mm}$. $\mathrm{Hg}$

To ascertain whether the assumption is correct that in the age groups concerned the systolic blood pressure is more closely connected with B.S.A. than with the chronological age, 595 boys (excluding

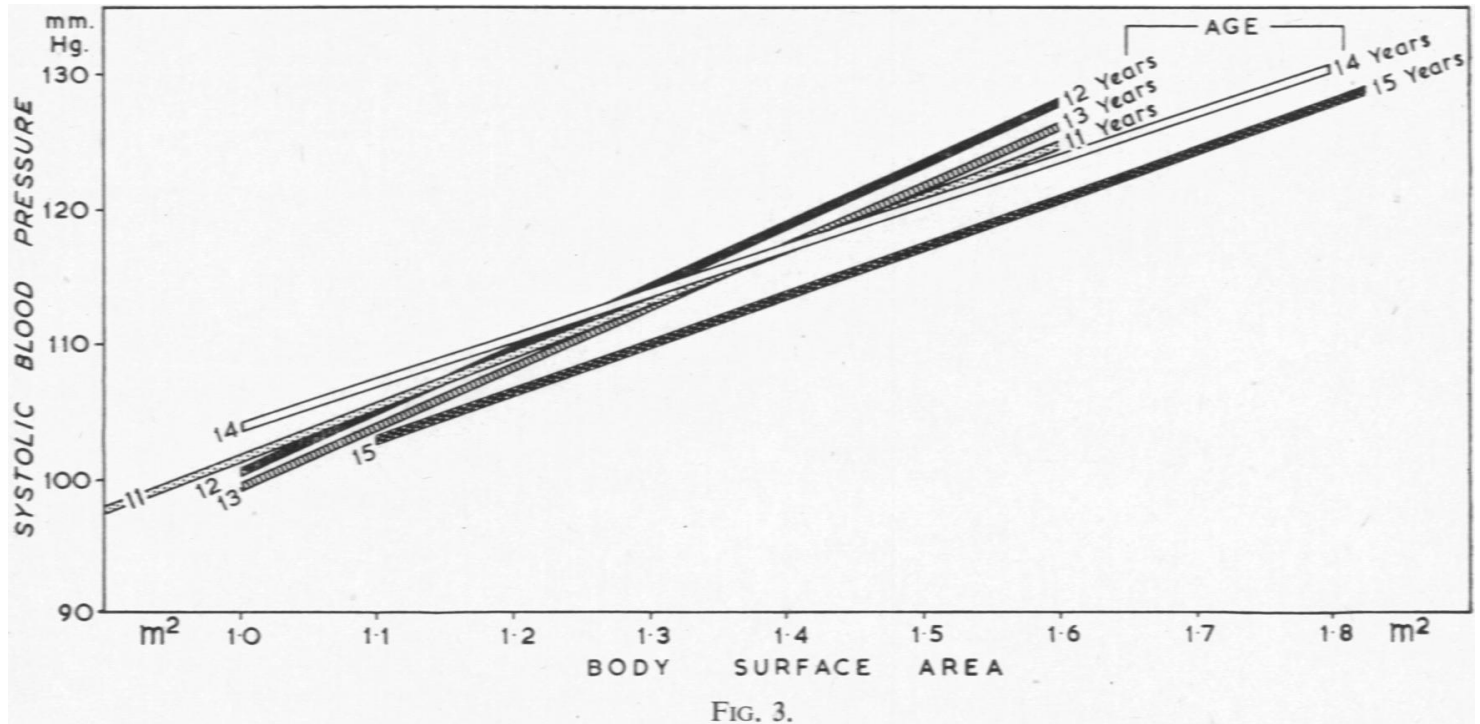

Graph representing regression equations blood pressure : body surface are in boys 11, 12,13,14 and 15 years of age. 
TABLE 10

Values of Systolic B.P. Calculated from the Regression Equation B.P. and B.S.A.

\begin{tabular}{|c|c|c|c|c|c|c|c|c|c|c|c|}
\hline \multirow[b]{2}{*}{ Age } & \multicolumn{11}{|c|}{ Body Surface Area } \\
\hline & 0.9 & $1 \cdot 0$ & $1 \cdot 1$ & $1 \cdot 2$ & $1 \cdot 3$ & $1 \cdot 4$ & $1 \cdot 5$ & $1 \cdot 6$ & $1 \cdot 7$ & $1 \cdot 8$ & $1 \cdot 9 \mathrm{~m}^{2}$ \\
\hline $\begin{array}{l}11 \cdot 5 \\
12 \cdot 5 \\
13 \cdot 5 \\
14 \cdot 5 \\
15 \cdot 5\end{array}$ & $97 \cdot 1$ & $\begin{array}{r}101 \cdot 2 \\
100 \cdot 7 \\
99 \cdot 2 \\
104 \cdot 0\end{array}$ & $\begin{array}{l}105 \cdot 3 \\
105 \cdot 3 \\
103 \cdot 8 \\
107 \cdot 3 \\
103 \cdot 0\end{array}$ & $\begin{array}{l}109 \cdot 4 \\
109 \cdot 9 \\
108 \cdot 4 \\
110 \cdot 6 \\
106 \cdot 6\end{array}$ & $\begin{array}{l}113 \cdot 5 \\
114 \cdot 5 \\
113 \cdot 0 \\
113 \cdot 9 \\
110 \cdot 2\end{array}$ & $\begin{array}{l}117 \cdot 6 \\
119 \cdot 1 \\
117 \cdot 6 \\
117 \cdot 2 \\
113 \cdot 8\end{array}$ & $\begin{array}{l}121 \cdot 7 \\
123 \cdot 7 \\
122 \cdot 2 \\
120 \cdot 5 \\
117 \cdot 4\end{array}$ & $\begin{array}{l}128 \cdot 3 \\
126 \cdot 8 \\
123 \cdot 8 \\
121 \cdot 0\end{array}$ & $\begin{array}{l}131 \cdot 4 \\
127 \cdot 1 \\
124 \cdot 6\end{array}$ & $\begin{array}{l}130 \cdot 4 \\
128 \cdot 2\end{array}$ & $\begin{array}{l}133 \cdot 7 \\
131 \cdot 8\end{array}$ \\
\hline
\end{tabular}

cases of pituitary obesity) between 11 and 14 years were collected, 175 were $11 \cdot 5$ years old; 117 , $12 \cdot 5$ years old; $109,13 \cdot 5$ years old and $194,14 \cdot 5$ years old. Their systolic B.P. values were plotted against their B.S.A. irrespectively of age. Only the class intervals $0 \cdot 9,1 \cdot 7$ and $1 \cdot 8 \mathrm{~m}^{2}$ were omitted since the number of observations was too small. The means of the actual blood pressure observations for each class of $0.5 \mathrm{~m}^{2}$ are shown as circles in Fig. 4 and the line in the graph represents the regression equation for the whole series: B.P. $-112 \cdot 7=35 \cdot 8$ (B.S.A. $-1 \cdot 29$ ) or B.P. $=35 \cdot 8$ B.S.A. $+66 \cdot 5$. These means lie approximately on a straight line.

\section{Conchusions}

- Growth', as Washburn (1950) writes, 'does cover a multitude of phenomena but there is a unity which binds them together. As we observe it in a growing child it does include increase in height, in weight, in size of organs; it also includes increasing functional facilities and powers of adaptation to varied environmental influences.' The findings of my statistical study show that arterial blood pressure during puberty in boys follows the laws of growth at this third period of acceleration of growth. At about 13.5 years the average boy spurts in his blood pressure as he does in his height, weight and surface area as well as in the size of heart. But, as in all the last mentioned items, the range of variation in individual values is so wide that mean, median and mode do not provide the answer to the question as to whether the B.P. in a given boy is normal or abnormal. A systolic B.P. of $120 \mathrm{~mm}$. $\mathrm{Hg}$ in a 14-year-old boy can mean 'normo-', hyper- or hypotension according to his respective physique, and even a B.P. of $135 / 85$ might be normal for a 14-year-old boy if warranted by his physique. Only by correlating B.P. and body measurements can an approach be sought to establish values of individual normality. Whether the correlation existing between B.P. weight, height and body surface area represents facts of coordination, all of them due to the impact of somatotropic and adrenocorticotropic hormones

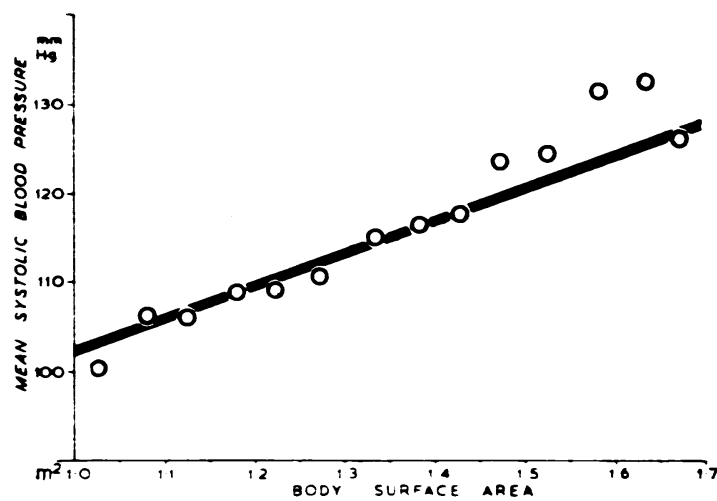

Fig. 4.-Regression equation blood pressure: body surface area in 595 boys 11-14 years of age and observed means of systolic blood pressure. Line represents regression equation: B.P. $-112 \cdot 7=35 \cdot 8$ (B.S.A. - 1 29). The groups 1.7 and $1.75 \mathrm{~m}^{2}$ are excluded because of their small number.

released by the anterior lobe of the pituitary to an increased extent during puberty, or whether the arterial B.P. just obeys the functional demands of the growing organism remains a question that is outside this survey.

The formulae given in this paper are proposed to enable us to estimate the normality or abnormality of B.P. values in a given individual belonging to the age groups under consideration.

\section{Summary}

A study of the blood pressure in 1,417 schoolboys aged 11 to 15 years is presented.

Mean, standard deviation, range and percentage distribution of systolic and diastolic blood pressure were determined, the correlation between systolic and diastolic blood pressure ascertained, and formulae established from the regression equations.

The correlation of systolic blood pressure, weight, height and body surface area was analysed and formulae given for the determination of the normal individual blood pressure, using the regression equations. 
The study reveals (1) that there is a wide variation of systolic and diastolic blood pressure which becomes more marked once puberty starts. (2) Systolic and diastolic blood pressure 'spurts' with the beginning of puberty, i.e. at the same time as the third period of acceleration of growth. (3) Of the $11 \cdot 5$-year-old boys $78 \cdot 1_{\%}^{\circ}$, and $70 \cdot 5^{\circ}$ o of the 12.5-year-old boys have a systolic blood pressure between 90 and $119 \mathrm{~mm}$., whereas threequarters of the $13 \cdot 5$ - to $15 \cdot 5$-year-old boys exhibit a systolic blood pressure between 100 and $129 \mathrm{~mm}$. Of the $15 \cdot 5$-year-old boys, $62 \cdot 3^{\circ} \%$ have a systolic blood pressure between 110 and $139 \mathrm{~mm}$. About three-quarters of the 11-, 12- and 13-year-old boys have a diastolic blood pressure between 50 and $69 \mathrm{~mm}$. $\mathrm{Hg}$, whereas 72.5 and $81 \cdot 8^{\circ}$ o of the 14 and 15-year-old boys show a diastolic blood pressure within the range of $60-79 \mathrm{~mm}$. $\mathrm{Hg}$. There is a statistically significant correlation between systolic and diastolic blood pressure.

To ascertain what might be considered the individual normal blood pressure the correlation between blood pressure and anthropometric measurements was determined. It is positive for weight, height and body surface area, being closer with weight and body area than with height. The association between blood pressure and growth is higher than that of blood pressure and age for the age groups under consideration. Generally each boy has the blood pressure of his physiological age.

The correlation of blood pressure, weight and body surface area permits the prediction of the normal blood pressure for the individual from the respective regression equation, and formulae to this effect are presented.

I wish to thank Dr. E. K. Macdonald, Medical Officer of Health, City of Leicester, for his permission to publish this paper and for his helpful suggestions during its preparation.

\section{REFERENCES}

Alvarez, W. C. (1920). Arch. intern. Med., 26, 381.

Alvarez, W. C. and Stanley, W. (1930). Arch. int. Med. 46, 17.

Ellis, R. W. B. (1950). Brit. med. J., 1, 85.

Faber, A. Quoted from Kylin.

Hahn, L. (1924). Zbl. inn. Med., 45, 946. (1951). Med. Offr., 85, 43.

Hines, E. A. (1937). J. Amer. med. Ass., 108, 1249.

Koller, S. (1936). 'Statistik der Kreislaufkrankheiten.' Dresden.

Kylin, E. (1937). 'Der Blutdruck des Menschen.' Dresden.

Müller, C. (1921). Acta med. scand., 55, 381, 443.

Paterson, D. and Moncrieff, A. (1949). 'Diseases of Children,' 4th ed., vol. 2, p. 680.

Robinson, S. C., and Brucer, M. (1939). Arch. intern. Med., 64, 409.

- (1940). Ibid., 66, 393.

Schlesinger, B., and MacCarthy, D. (1949). In Garrod, Batten and Thursfield, "Diseases of Children, 4th ed., ed. D. Paterson and A. Moncrieff, vol. 2, p. 680 .

Sutcliffe, A., and Canham, J. W. (1950). 'The heights and weights of boys and girls.' London.

Taussig, H., and Hecht, M. S. (1938). Bull. Johns Hopk. Hosp., 62, 510.

Washburn, A. H. (1950). Pediatrics, Springfield, 5, 765. 


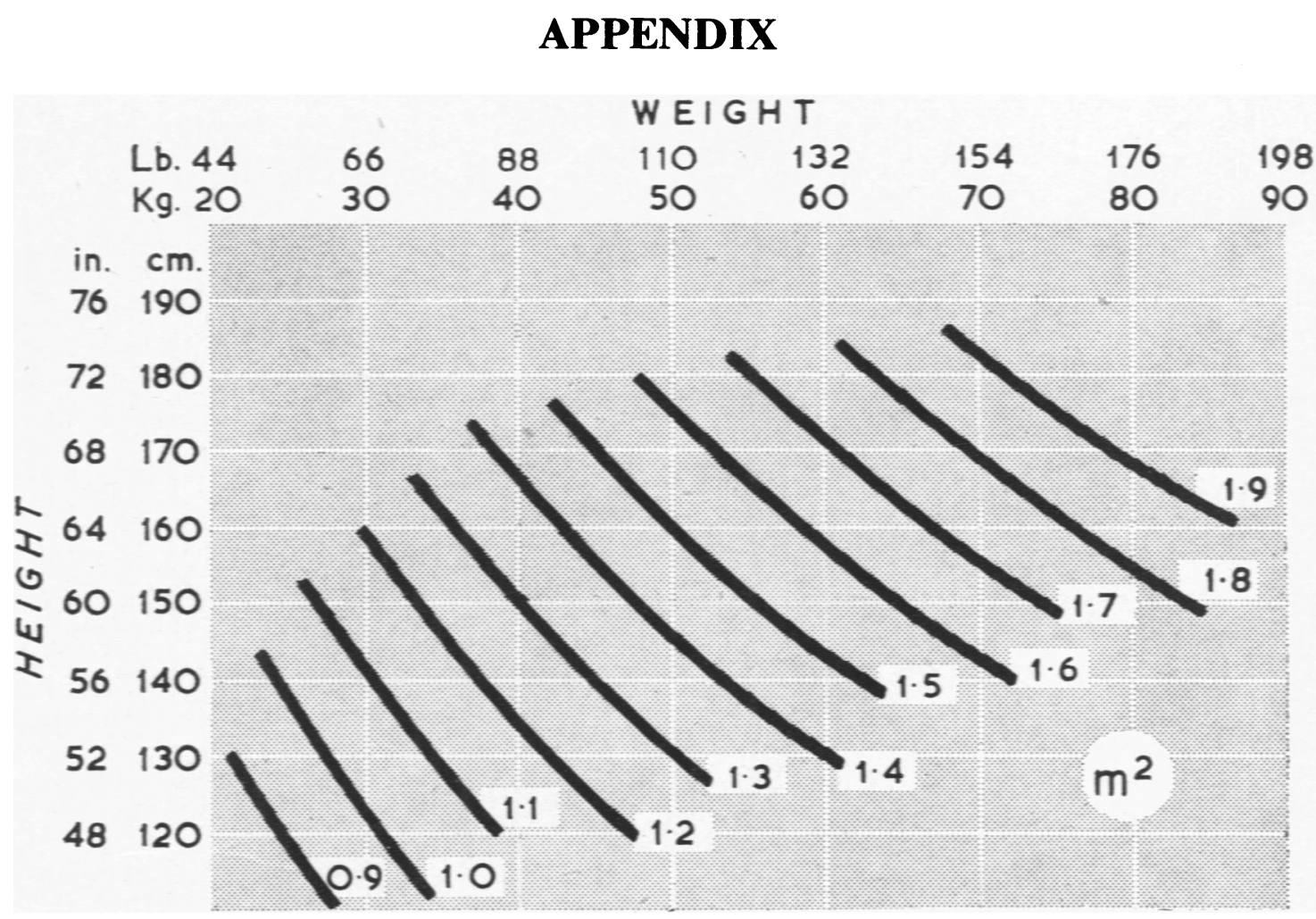

Graph for the determination of body surface area applying Dr. Bois's formula (B.S.A. = weight $(\mathrm{kg}$.) $0.425 \times$ height $(\mathrm{cm}) .0.725 \times 71 \cdot 84)$ 